\title{
Analysis on Influences of Physical Exercise on Personality of College Students \\ Yanru Li
}

\author{
School of physical education, Shaanxi Normal University, Xi'an, 710119, China
}

Keywords: College students; physical exercise; personality

\begin{abstract}
Many college students pay less attention to sports class, prefer free activities in sports class and do not care about sports items, which seriously affect the real significance of physical exercise. The practice shows that the influence of sports on the personality of college students is very important. The influence of physical exercise on the personality of college students is analyzed in this paper to define the significance of sports in promoting the development of college students.

Nowadays, with the continuous promotion and development of new curriculum reform, the educational problem of students has been improved greatly and a great achievement has been made. At present, physical exercise of college students has become an important course. The practice shows that a few college students are interested in sports, thus greatly reducing the function of physical exercise. Physical exercise is closely related to the personality development of college students. Therefore, the teacher is obliged to improve the understanding of college students at this aspect and guide the students to actively participate in physical exercise to sublimate the personality of college students in participating in physical exercise so as to have a healthy growth.
\end{abstract}

\section{Analysis of personality research of college students}

The personality research of college students is conducted mainly from three aspects: personality connotation, personality characteristic and personality measurement. The research on the personality of college students can be more concrete only from the three aspects.

(I) personality connotation analysis

Alpert, as the founder of personality, thinks: "Personality is the internal dynamic structure of the psychosomatic system that determines the unique environmental adaption method". From the nature and depth of this definition, its comprehensiveness is strong, so this statement is favored by relevant researchers. However, it is thought that the personality and character are closely related and the personality is an embodiment of character, which is important to the personal development with the features of individual tendency unity. The personality is a tendency of individual and its behavior and at the same time, the personality is an embodiment of the development change of an individual, characterized by consistency and continuous persistence. Chinese researchers define the personality as follows by research: it is the whole manifestation of the stable and important psychological features of an individual, in which the psychological features are personal ability, temperament, interest, hobby, tendentiousness and other aspects, which are based on the physiological quality and formed and developed by social practice and human growth.

(II) personality characteristic analysis

At present, the researches with regard to the personality lack of clear definition, but many research conclusions have similar views in the significance of understanding of personality nature, among which the researchers highlight or admit the personality integrity, stability, complex and uniqueness. Therefore, the essence and features of personality are grasped if the four natures of personality are included and its definition will have no great deviation.

(III) personality characteristic analysis

At present, there are more than 100 testing researches of personality measurement. The main testing types mainly include questionnaire method, projection method, behavior observation method, rating method and situational method from the compiling method and measuring procedure, in which certain achievement has been made and certain recognition has been obtained. At present, Carte 16PF, Minnesota multiphasic personality inventory and other measuring tools are mainly used 
to measure the personality of college students, but these measuring tools are generated under the western cultural background and have certain limitation in China from its essence because the investigation and research on the personality measurement of college students in China are less and the application of these measuring tools and methods have certain drawbacks.

\section{Analysis of the research status of college students' personality at this stage}

The personality problem in psychology has always been a focus concerned. Recently, the foreign countries have made achievements at the personalty research of college students, which are outstanding in self and personality, race and personality and personality research method. As early as 20 years ago, the psychologists in China have studied the personality and the personalty research field has been expanded effectively in the personality exploration road recently, in which certain achievements have been made. For example, great achievements have been made in research of youth value and cultivation education research of students' healthy personalty.

At present, there are many researches of college students' personality, with wide aspects involved, such as college students' psychological health, social support, self-esteem, time management tendency and other aspects. Among the present researches, the personalty of college students, copying style and other aspects are mainly studied, which is helpful for teachers to master the college students' psychology and personality. In addition, Chinese researchers also study the personality development and psychological reaction of impoverished college students. The researcher finds in studying the personalty features of college students that the personality development is closely related to the psychological health and also an important mediating variable of social support and psychological health.

The factors imposing bad influences on the psychological health of college students are mainly personality introversion, emotional instability and psychotic features. According to the investigation, the characters of students with different major, sex and grade and from the urban and rural areas are different to a certain degree. To get the best effects of physical exercise, the teacher should concern every students, master their different character and develop different sports teaching scheme to promote students to conduct physical exercise positively.

\section{Analysis of the research status of physical exercise and college students' personality}

China, the influence of physical exercise on personality of college students is rarely studied, the research method is single and the research is not systematic and perfect. In addition, the research is scattered, without mature theory.

(I) Analysis with College students of sports major as the research object

Generally, the personality research of college students of sports major is studied and the personality features and the personality difference of college students of non-sports major are analyzed and studied. Generally, for college students of sports major, the students with good theoretical performance and technical performance have sociability, intelligence, persistence and other features in character performance. Some researchers state that college students of sports major and non-sports major are not different in internal extroversion and personality features, but greatly different in other aspects.

(II) Analysis of personality research of college students of non-sports major

The personality of college students of non-sports major is studied mainly from personality features, sports interest, participation degree, physique and other aspects. The personality of human exists mainly because the personality factor can promote the improvement and development of the psychological health, sports ability and level of human, which is an important psychological basis for enhancing the students' physique. In China, the personality features, sports participation and other aspects of college students are studied and analyzed to a certain degree and it is found in the research that the personalty of college students will be extroverted with low neuroticism with the increase of sports participation degree; college students with psychotic personality will be affected by the sports participation frequency and the personalty features will affect the sports participation 
degree. At the same time, to promote the healthy and perfect personality development of college students in China, sports teachers should effectively guide the sports of college students to ensure its healthy development. Once the personality features of college students are carefully investigated and studied by questionnaire and the physique and health of many students are tested. The results show that the human features and physical health are at a high level. The physical health of introverted college students is at a low level.

(III) Analysis of personality research of high-level college students

With high-level college students as the research object, the personality features of different sports items and sports injury are analyzed. Once the sports injury and personality features of college student athletes are studied and the results show the injury of athletes is closely related to their personality features and their stubbornness and personality features are obviously associated with the injury of athletes. However, the injury of athletes is rarely correlated to their emotion and imperceptibility. Compared with the sports major, the sports injury has high tonicity and anxiety and the stability and self-control are poor. The sports injurer with different sex and personality features are different in anxiety and stability to a certain degree, for which the anxiety of men is lower than women, but the stability of men is higher than women. However, the personality features of sports injurer are not greatly changed before and after injury.

It is known that the there are many scattered researches at this aspect at present, lacking of systematic and in-depth empirical research. The difference between personality features of college students of sports major and non-sports major is mainly studied from the analysis of the influences of psychical exercise on the personality of college students; for the personality features of ordinary college students, the personality and sports interest, sports participation degree and physique of college students are mainly studied; for high-level college students, the personality features embodied in different sports items and sports injury are studied to a certain degree. The research items are different, but an agreed conclusion is made: "Physical exercise plays a positively role in promoting the personality shaping of college students."

\section{Deficiency of personality research and analysis of future development trend}

At present, the personality research is deficient, for example, the personalty measurement tools and methods are not mature at present. The research method at this aspect is generated under the western cultural background, it has great limitation in China. So it is important to develop the measuring tools application to China through continuous development.

In addition, the scope of research objects should be expanded to a certain degree. The personality research should not only stay on the college students of sports major and the students of other major, special group and minority should also be investigated and studied to ensure the comprehensiveness, reality and effectiveness of research combined with the different major, age, sex and other aspects.

At last, the personality research of college students should refer to the psychology and education in the future development, which is beneficial to enrich and expand the thinking and vision of research of physical exercise and college students' personality. It should be noted that the personality with certain stability and continuity grows and develops under continuous changes to be healthy and perfect after a long time.

\section{Conclusion}

Nowadays, with the social development, the number of college students increases and the state pays more and more attention to the educational problem of college students in sports. Many college students do not like sports to make the sports lose its original meaning. However, the physical exercise is of important significance in the personalty development of college students. The personality research of college students as well as the research state of physical exercise and college students' personality are analyzed from the meaning of personality in this paper to know the influence of physical exercise on college students' personality. In addition, it is found from the personality research of college students that the personality of college students is different to a 
certain degree due to different major, character, grade and region. Therefore, to ensure good effects of physical exercise, the sports teacher should carefully observe each student and respect the difference to promote the healthy development of personality in physical exercise.

\section{Acknowledgments}

This paper is 2014 Education Science "12th Five-Year” Plan Project of Shaanxi Province, number: SGH140558.

\section{References}

[1] Cai Wucheng. Research on Influences of Sports on Psychological Health of College Students[J]. Fujian Sports Science and Technology, 2002((06).

[2] Pan Hailin. Research and Discussion on Sports Psychological Quality of College Students[J]. Science \& Technology Information (Academic Research), 2008(29).

[3] Han Fengzhi, Meng Qingfu, Li Xianying. Research on Relationship between personality features and Participation of Physical Exercise of College Students[J]. Journal of Beijing University of Physical Education, 2005(05).

[4] Li Yongxin, Li Yimin. Research on Psychological Health and Socially Supportive personality Characteristic of College Students of Sports Major[J]. Chinese Journal of Behavioral Medicine and Brain Science, 2004(06).

[5] Zhang Fusheng. Research on personality Characteristic and Physical Health of College Students[J]. Journal of Beijing University of Physical Education, 2005(10). 